\title{
GPR Application for Risks Detection in Subsurface Engineering Construction Projects
}

\author{
Gamil Alsharahi, Ahmed Faize, Carmen Maftei, Abdellah Driouach
}

\begin{abstract}
The aim of this work is to study and explore the causes of the landslide in different locations using Ground Penetrating Radar (GPR) technology. GPR uses the electromagnetic method related the high-frequency pulse that used widely in various field. The experimental study focused on the investigation of the landslide in the road by GPR method with antenna $200 \mathrm{MHz}$. The landslides become serious problems and required various technique and methods to investigate it in several places. GPR measurements present a useful technique for studies and investigation of the problem. The GPR can be categorized in the first place as an experimental method surveys landslide depths were recognized at 1-10 $\mathrm{m}$ below the natural terrain level. The results obtained revealed the causes of landslides on the road.
\end{abstract}

Keywords - cavity, detection, GPR, landslide, methods, risk

\section{INTRODUCTION}

Ground Penetrating Radar (GPR) is an imaging technique that uses wide-band electromagnetic waves to images of the subsurface typically from $0-10 \mathrm{~m}$ depth. GPR is an effective tool for subsurface inspection and quality control on engineering construction projects. The survey method is rapid, nondestructive. GPR has been successfully applied to a very wide range of tasks ranging from mapping geological structures, to identifying defects in concrete and roads.

Landslide is defined as the movement of a mass of rock, debris or earth down a slope (Cruden, 1991); it is a local phenomenon controlled by different internal / external factors like topographic, geological, climate conditions, etc. Land use activities can contribute to the occurrence of landslide [1].

Recently, the landslides present major problems in the built environment such as buildings, roads, and railways. In England, at last, 10000 years, most landslides were dramatically and due to the glacial and pre-glacial activity. Landslides present a considerable variation in depth at the slip surface and in the nature of slip debris [2]. Further, the situation can be complicated by the presence of water and the complex proprieties of the clay. The GPR is the most likely used to investigate and identified the landslide for its ability [3]. In the other hand traditional techniques taking attention for landslide investigation such as seismic refraction and vertical electrical soundings [4]. It accuracy technique for the landslide which characterized by higher moisture and porosity values. A review of the geophysics slop stability has presented scribes all modern geophysical approaches, including GPR [5]. 
The application of GPR has several difficult and problems to characterize the landslide and slope stability analysis due of the particular, high attenuation of common slide materials (e.g. clays) and the significant depth of most slide structures. The GPR has been used in the North Cotswolds by Raines et al. (1999) with 225 and $50 \mathrm{MHz}$ antennae, to delineate the internal structure of gulls and cambered strata of the Inferior Oolite Group of Jurassic age [6]. The signal of penetration was between 5 and $6 \mathrm{~m}$ on cambered limestone, reducing to $2-3 \mathrm{~m}$ over the mainly clay filled gulls. Similarly, the GPR investigation was used in northern of Italy, using $225 \mathrm{MHz}$ antenna were performed to assess the depth and geometry of rock slides and buckles affecting a dip slope of regularly stratified limestone's interblended with marly-clayey horizons in the south-eastern Alps [2].

The choosing of this method was of the absence of high cuts in the rocks mass, presence of debris and loosened slabs on the slope did not allow the geometry of the sliding mass to be described solely by means of field mapping. The GPR has been with $50 \mathrm{MHz}$ antenna to detect the internal rupture surfaces of a debris flow affecting the lower part of the "Les Paillettes" landslide in the Rhone valley In the western Swiss Alps. The presented results show that the GPR is able to identify an image down at $40 \mathrm{~m}$ depth within schist's and show the groundwater table at $10 \mathrm{~m}$.

Generally, as presented in all papers at literature the GPR profiles are able to identify the subsurface boundaries of a rapid debris flow. Furthermore, the above examples show that conductive shallow layers often limit the effectiveness of the GPR method, and its successful application on landslides is expected to strongly site dependent [7].. Due to unknown geological condition ahead in tunnel construction, undesirable geological factors are often encountered, such as fault, crushed zone, karst cave and Underground River. These geological factors not only influence tunnel excavation speed, but also cause severe engineering accidents such as collapse, debris flow, water burst and other destructive geological disasters [8].

In sedimentary geology, ground penetrating radar (GPR) is used primarily for stratigraphic studies where near-continuous, high-resolution profiles aid in determining: stratigraphic architecture; sand-body geometry, and correlation and quantification of sedimentary structures. In the past, to investigate lateral continuity and variability of sediments, we had to infer the correlation between boreholes, outcrops or shallow trenches [9-11].

\section{INVESTIGATION METHODOLOGY AND MATERIALS}

$\mathrm{T}$ The experimental measurement was conducted using GPR equipped with the antenna in the frequency range $200 \mathrm{MHz}$. The results were carried out along the road in city Tetouan as presented in the figure.

The GPR equipment employed in this study comprises a $400 \mathrm{MHz}$ transceiver (an antenna that is both the emitter and receiver of signal), a $200 \mathrm{MHz}$ transceiver, an SIR-3000 GPR data control and recording system, and a survey wheel for measuring distance, all from Geophysical Survey Systems International (GSSI) [10-13]. 


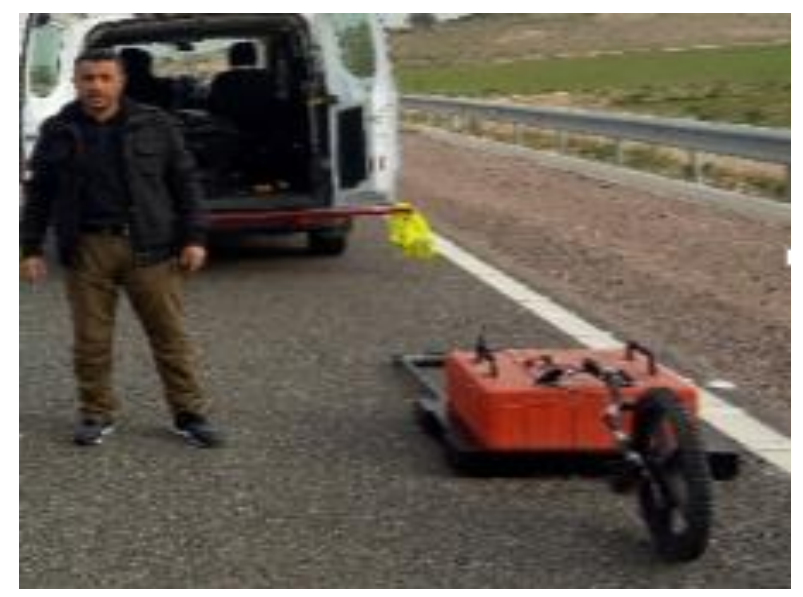

Fig. 1. Antenna methodology survey

\section{RESULTS OF INVESTIGATION}

In Morocco, about $380 \mathrm{~km}$ of the motorway network is considered "very exposed" to landslides and 3 watersheds considered as "floodable". The company has launched technical protection and prevention projects to control landslide risks. Regarding erosion, initiated the project "Al Arde" which aims to stabilize the soil, using the techniques of biological engineering. The goal is to multiply wild seeds along the highways to vegetate up to 10,000 hectares of land. Figure 2 presents an example from the road with landslide [12].

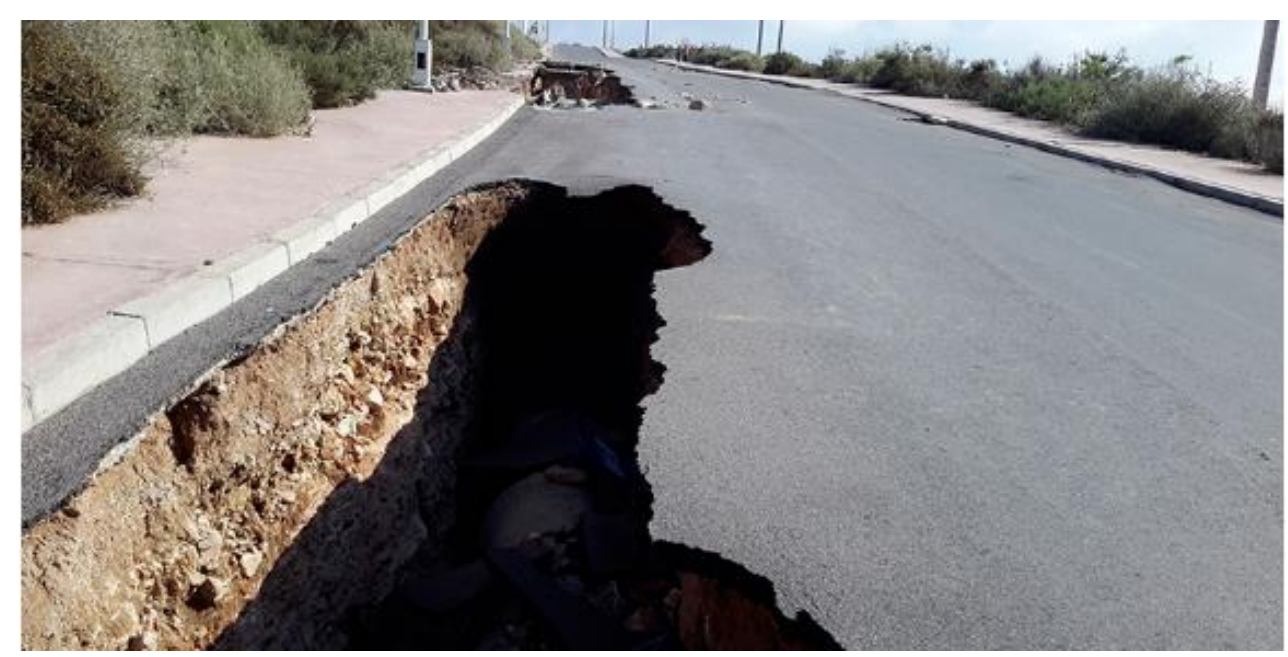

Fig. 2. Example landslide in road

Experimental studies carried in various place in Moroccan road using GPR. Figures 35 present the radargrams of the obtained results. These figures illustrate the slop and cavity under subsurface can cause a landslide.

The study area is located at city Tetouan in a coastal area several active landslides occur. This work was divided into three zones and samples were taken for discussion in this work. 


\section{sciendo}

54 Ovidius University Annals Series: Civil Engineering, Year 21, 2019

\section{Zone 1}

In this zone we noticed some distortions and slope in the layers of the earth under the road, which may cause damage in the future. These distortions began from $2 \mathrm{~m}$ depth to more than $5 \mathrm{~m}$ as Figure 3.

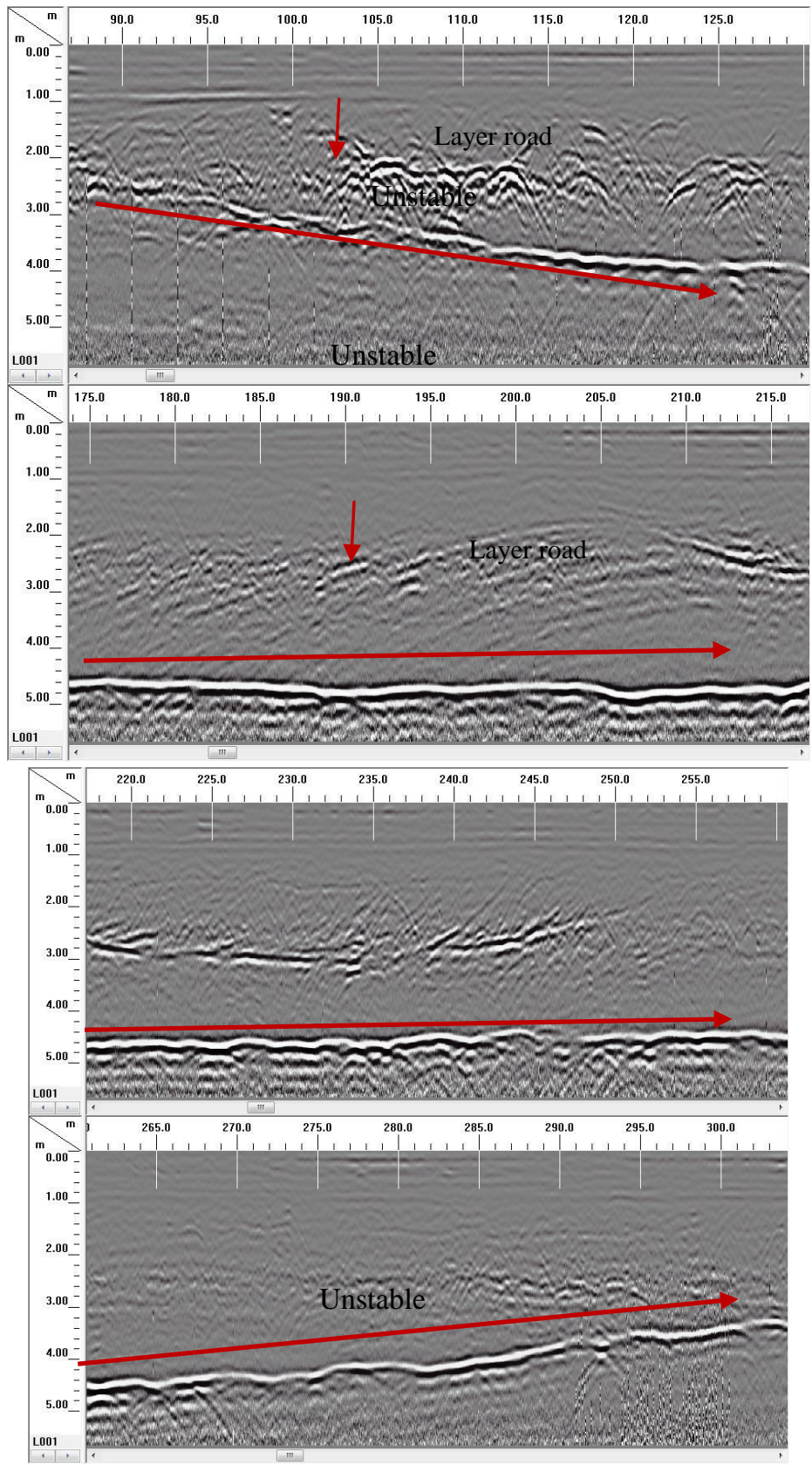

Fig. 3. Slop under subsurface in zone 1 


\section{sciendo}

Ovidius University Annals Series: Civil Engineering, Year 21, 201955

\section{Zone 2}

In the second zone we found the boundary (slop) between the two layers at a depth of more than the first zone up $4.2 \mathrm{~m}$ to $5.2 \mathrm{~m}$.

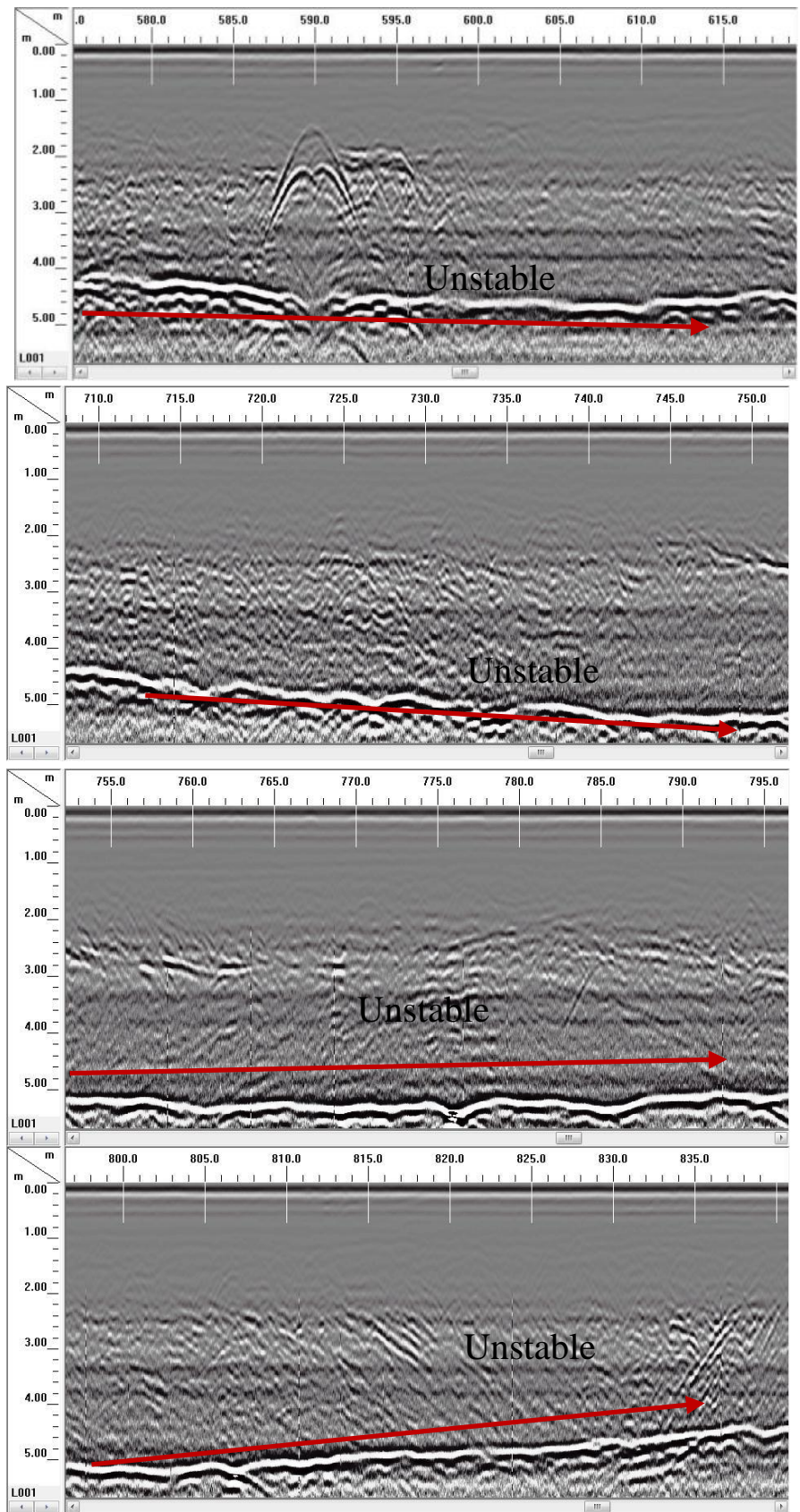

Fig .4. Slop under subsurface in zone 2 


\section{sciendo}

56 Ovidius University Annals Series: Civil Engineering, Year 21, 2019

\section{Zone 3}

In the third zone were many changes and the occurrence of crashes and cracks in the road because of the existence of some cavities and also the slope between the two layers.

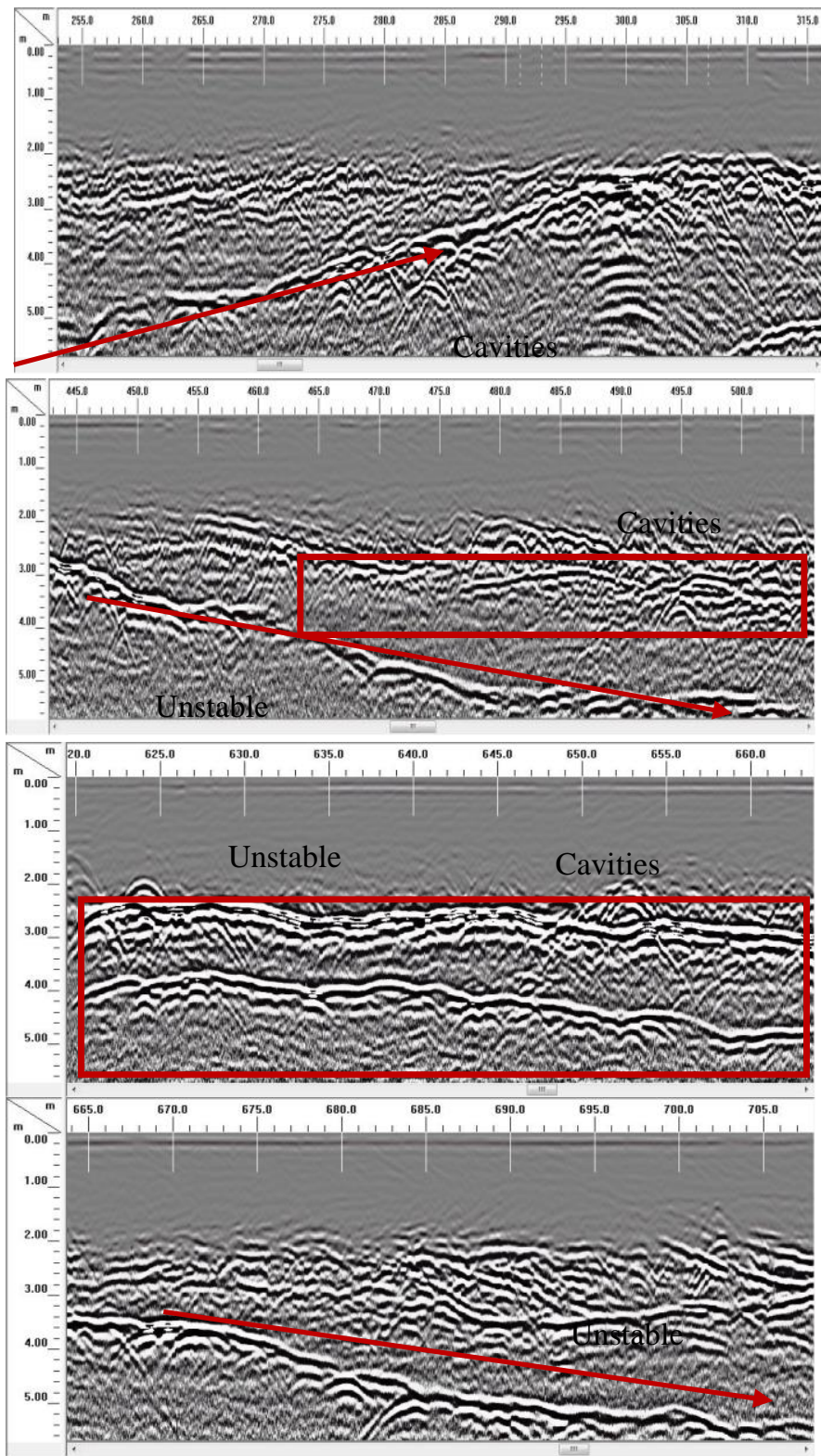

Fig .5. Slop under subsurface in zone 3

The GPR observations allow detecting different soil layer at the subsurface with successive high-amplitude horizontal reflectors until the depth of $10 \mathrm{~m}$. The horizontal reflectors can be interpreted as a significant contrast between the two layers. This 
distinction is probably related to a difference in the composition of the road structure or related to the presence of groundwater. No drilling was possible to confirm this hypothesis.

\section{CONCLUSIONS}

The radargrams in the paper described presently the usage of the GPR method in studying landslides. In this work, we found horizontal landslides due to the slope between two layers and vertical landslides due to the presence of cavities and slope at the same time. On the one hand, grounding on the research of landslide in Morocco, it may be asserted that it produces good results and it furthers the recognition of the right slide surface. In fact, any case of landslide research by means of the GPR method should be analyzed separately. The GPR method, like any geophysical method, produces the best results in favorable conditions.

\section{REFERENCES}

[1] Alsharahi G., Mostapha, A.M.M., Faize A., Driouach A., 2016. Modelling and simulation Resolution of GroundPenetrating Radar Antennas. J. Electromag. Eng. Sci. 16 (3), $182-190$

[2] Alsharahi, G., Mostapha, A.M.M., Faize, A., Driouach, A., 2016. 2D FDTD simulation to Study response of GPR Signals in homogeneous and inhomogeneous mediums. Int. J. Commun. Ante. Propag. 6 (3), 153

[3] Alsharahi G., A. Faize, M. Louzazni , A.M.M. Mostapha, M. Bayjja, A. Driouach. Detection of cavities and fragile areas by numerical methods and GPR application, Journal of Applied Geophysics 164 (2019) $225-236$

[4] Bichler A. et al., "Three-dimensional mapping of a landslide using a multi-geophysical approach: the Quesnel Forks landslide," Landslides, vol. 1, no. 1, pp. 29-40, Mar. 2004

[5] Bichler A., Bobrowsky P., Best M., Douma M., Hunter J., Calvert T., BurnS R., Threedimensional mapping of a landslide using a multi- geophysical approach: the Quesnel Forks landslide, Landslides, 2004, 1(1), 29-40

[6] Busby, J.P.; Cuss, R.J.; Raines, M.G.; Beamish, D, "Application of ground penetrating radar to geological investigations," Appl. Ground Penetrating Radar Geol. Investig., 2004

[7] Lissak C., O. Maquaire, J.-P. Malet, F. Lavigne, C. Virmoux, C. Gomez, and R. Davidson. Ground-penetrating radar observations for estimating the vertical displacement of rotational landslides, Nat. Hazards Earth Syst. Sci., 15, 1399-1406, 2015

[8] McCann D. M. and A. Forster, "Reconnaissance geophysical methods in landslide investigations," Eng. Geol., vol. 29, no. 1, pp. 59-78, Jun. 1990

[9] Raine D., E. G. Thomas, and E. G. Thomas, An Introduction to the Science of Cosmology, CRC Press, 2018

[10] Richard J. Yelf, Georadar Research Pty Ltd, 412 Eastbank Road, Coramba, Coffs Harbour, NSW 2450, Australia

[11] Sass O., R. Bell, and T. Glade, "Comparison of GPR, 2D-resistivity and traditional techniques for the subsurface exploration of the Öschingen landslide, Swabian Alb (Germany)," Geomorphology, vol. 93, no. 1-2, pp. 89-103, Jan. 2008

[12] Wai-Lok Lai W., X. Dérobert, and P. Annan, "A review of Ground Penetrating Radar application in civil engineering: A 30-year journey from Locating and Testing to Imaging and Diagnosis," NDT E Int., vol. 96, pp. 58-78, Jun. 2018 
[13] Zhao C., S. Li, J. Wu, Z. Xu, Y. Zhang, and L. Zhou, "Case study of Ground Penetrating Radar for geological prediction in Qiyueshan Tunnel," in Proceedings of the 2nd International Conference on Green Materials and Environmental Engineering, Phuket, Thailand, 2015.

Note:

Gamil Alsharahi - Abdelmalek Essaâdi University, Faculty of Sciences, Department of Physics, Tetouan, Morocco, Ovidius University of Constanta, Faculty of Civil Engineering, Department of Civil Engineering, Constanţa, Romania (Corresponding author to provide phone: +40-759656974; e-mail: alsharahigamil@gmail.com)

Ahmed Faize - Mohammed 1st University, Faculty of Polydisciplinary, Department of Physics, Nador, Morocco (e-mail: ahmedfaize6@hotmail.com)

Carmen Maftei - Ovidius University of Constanta, Faculty of Civil Engineering, Department of Civil Engineering, Constanţa, Romania (e-mail: cemaftei@gmail.com)

Abdellah Driouach - Abdelmalek Essaâdi University, Faculty of Sciences, Department of Physics, Tetouan, Morocco (e-mail: cadriouach@hotmail.com) 